\title{
ALTERATION IN RESPIRATORY RHYTHM IN SURGICAL ANAESTHESIA
}

\author{
By WILLIAM W. MUSHIN, M.B., B.S., D.A. \\ (Honorary Anaesthetist, Seamen's Hospital, Greenwich, and Central London Throat, Nose and Ear \\ Hospital; Anaesthetist, Royal Dental Hospital; Anaesthetist, E.M.S.)
}

Breathing combines for us the functions of carburettor and exhaust. It provides a means of taking in sufficient oxygen to satisfy metabolic needs, and of expelling carbon dioxide, the product of organic combustion. It is, therefore, rational that respiratory activity should be controlled by the stimuli of oxygen need and carbon dioxide accumulation. Carbon dioxide, however, is also an essential constituent of the blood in the form of sodium bicarbonate, the most important "buffer" substance resisting change of blood reaction. There is thus an optimum amount of carbon dioxide in the blood stream, and respiration is responsive to carbon dioxide deficiency as well as excess. In addition to the two primary and essential functions of oxygen intake and carbon dioxide expulsion, the respiratory apparatus forms a convenient way of introducing volatile drugs into the body to produce anaesthesia. In doing this, the anaesthetist may unwillingly or unwittingly disturb the patient's respiration. For example, the drug he uses may, and in fact usually does, affect the respiratory centres in the brain, to a greater or lesser degree, or it may irritate the respiratory passages and produce reflex effects on the respiration. Again, the patient's airway may become obstructed by a relaxed tongue or even by some of the anaesthetist's paraphernalia.

Surgical anaesthesia is denoted by regular machine-like automatic respirations and it is essential that the anaesthetist should be on the look out for, and recognise, disturbances of the respiratory rhythm during anaesthesia. Having detected a departure from the "normal," an accurate diagnosis of its cause is a necessary pre-requisite of its correction, and the re-establishment of a state of affairs as little different to the normal physiological one as possible. Only by this combination of vigilance and knowledge is safety in anaesthesia ensured. The modern use of powerful pre-operative sedative drugs and mechanical methods of anaesthetic drug supply to the patient, make the detection and recognition of changes in the respiratory rhythm imperative, since they may be and often are the only means of detection of changes in blood oxygen and carbon dioxide.

The automatic rhythmic character of respiration is due to impulses arising from both inspiratory and expiratory centres in the medulla. Alternate reflex inhibition of these centres occurs from stimuli arising in the lung tissues at the moments of maximum inflation and maximum deflation (Hering-Breuer reflex). The centre (the inspiratory and expiratory centres are usually coupled and spoken of as one respiratory centre) is sensitive to an increased acidity of the blood, particularly when it is due to carbon dioxide, and responds by causing the breathing to become deeper and more rapid, i.e. hyperventilation. It is also sensitive in a lesser degree to oxygen want, and responds in similar fashion. The vitality of the centre, however, is rapidly impaired by oxygen deprivation, and it soon ceases to work altogether. Oxygen want produces its main effect by stimulating the pin-head-like carotid body situated at the bifurcation of the common carotid artery, and the similarly functioning aortic body, near the arch of the aorta. Thus when the blood going to the brain is suboxygenated, the carotid and aortic bodies are stimulated and produce reflex hyperventilation, particularly by an increase in respiratory rate.

The following is a description of some of the common disturbances of the "normal" automatic rhythm, which occur in the third stage of inhalation anaesthesia.

\section{APNOEA: OR CESSATION OF RESPIRATION}

(a) Early in 3 rd stage.

(i) Cessation of respiration was a commonplace in the days of open mask induction in unpremedicated patients. The deep breathing during the frequently turbulent induction, caused a depletion in the blood carbon dioxide with a resultant apnoea. When this type of apnoea occurs, no treatment is necessary as spontaneous breathing starts when the carbon dioxide accumulates sufficiently, or oxygen want occurs, whichever happens first.

(ii) When a "forced" induction with carbon dioxide in the inspired mixture is employed, the ether concentration in the brain may rise steeply while the rest of the body may contain 
little. This is due to the large carotid circulation, and the rapidity with which the brain takes up lipoid-soluble drugs, and occurs when any anaesthetic agent is rapidly introduced into the blood stream. As soon as the ether in the brain rises to a certain level the medullary centres cease to function, and the breathing ceases until the circulation has removed some of the ether. This type of apnoea occurring early in anaesthesia is also relatively harmless, and tends to pass off spontaneously, so long as no more ether is given and the circulation is unimpaired.

(b) Later in 3 rd stage.

(i) At any time during anaesthesia, especially in the light first plane, stimuli from the rest of the body may reflexly inhibit respiration and send the glottis into spasm. Such stimuli commonly arise from the abdominal viscera, periosteum, larynx, and the pelvic organs, particularly the rectum. Operations on these parts of the body require deep anaesthesia to avoid troublesome reflex effects on the respiration, and this is one of the reasons why endotracheal tubes, making deep anaesthesia easy and laryngeal occlusion impossible, are passed for an abdominal operation, and why spinal anaesthesia is popular for rectal operations.

(ii) Overdose of the agent may be the cause of an apnoea. Uncommon with ether, it easily and frequently happens when cyclopropane or chloroform is being used. This variety of apnoea is of quite different import to the early apnoea after a "forced" induction, since the general body concentration of drug is now high and separation of the drug from the brain to the blood is slow and takes place pari passu with the excretion of the drug from the blood to the alveoli. The combined effect of depressant drugs like cyclopropane, or large doses of morphia given before operation, with the use of a carbon-dioxide absorption circuit, frequently produces apnoea by a combination of a depressed centre, an inspired mixture containing little or no carbon dioxide and an abundance of oxygen, and a tendency for the alveolar carbon dioxide to be slightly lowered.

(iii) An excess of carbon dioxide ultimately paralyses the respiratory centre and produces apnoea, but the preceding stage of hyperventilation leading up to this will give the diagnosis. This uncommon but dangerous state of affairs is usually the result of forgetting to turn off the carbon dioxide after using it for induction, or to very exhausted soda lime in a circuit.

(iv) Oxygen lack will, of course, ultimately produce a cessation of respiratory activity after a preceding phase of hyperventilation and periodic breathing. It is usually accompanied by other and unmistakable signs of asphyxia, such as cyanosis and dilated pupils. However, anaemia may mask or prevent cyanosis, and morphia may mask the pupil changes, and when the oxygen want has developed insidiously, apnoea may be the first sign. This is the sort of thing which easily happens when nitrous-oxide and oxygen is inexpertly administered to shocked air-raid casualties who have been given large doses of morphia. Needless to say, apnoea due to oxygen lack is most dangerous and must be corrected by immediate artificial respiration with oxygen, intubating the larynx if necessary to ensure a perfect airway.

\section{HYPERVENTILATION}

(i) An increase in both amplitude and rate of breathing is caused by a raised tension of carbon dioxide in the blood. It is usually accompanied by a rise in blood pressure and pulse rate, and the surgeon begins to complain of the bleeding in the operation area. The patient's skin becomes flushed and he begins to sweat. Having made certain the airway is unobstructed the anaesthetist should reduce the amount of rebreathing (in the Boyle machine this is done chiefly by increasing the total volume of gases flowing), change the soda lime if an absorption circuit is in use, or see if he has not left the carbon dioxide running!

(ii) Oxygen want also causes hyperventilation particularly by an increase in the rate of breathing. The noisy hypernoea of deep nitrous oxide and oxygen anaesthesia is well known, and is, of course, an anoxic phenomenon. The diagnosis between a moderate degree of oxygen want and carbon dioxide accumulation is usually easily made by presenting the patient with a large amount of oxygen. If the hyperventilation is due to oxygen want his breathing will slow down and may even stop for a while. During anaesthesia oxygen want may be 'due to:

(a) Insufficient oxygen in the mixture. In this connection it is worth remembering that volatilized agents like ether occupy space when in the vapour state. A mixture containing just enough oxygen to keep the patient pink, may become inadequate to 
supply his oxygen requirements, when mixed with ether vapour. It has now been diluted, and each unit volume of nitrous oxide-oxygen-ether mixture contains less oxygen than before the ether was added.

(b) Obstructed airway.

(c) Inadequate tidal exchange due to such causes as a centre depressed by morphia, the intercostal paralysis of deep anaesthesia, Trendelenberg position, or compression of the patient's chest by assistants leaning on it.

(d) Decreased vital capacity due to pre-existing lung disease.

(e) Anaemia (including that due to sulphanilamide therapy), providing poor transport of oxygen to the tissues.

(f) Inability of the tissues poisoned with anaesthetic agent to utilise oxygen, i.e. oxygen want occurring in the midst of plenty.

(iii) Reflexly: One of the commonest causes of hyperventilation is reflex stimulation of the centre from the operation area. Common examples with which every anaesthetist is familiar are dilatation of the anal sphincter, and opening the peritoneum, under too light anaesthesia

\section{SLOWING OF RESPIRATION}

(i) Sedative drugs, especially of the morphia class, are now commonly given as premedication. They depress the respiratory centres and produce a slow breathing rhythm. In addition, the carotid body reflexes are depressed and made less responsive. If the sedative is given too soon before the operation, its maximum effect may come on during the operation, and the breathing will gradually slow down. This is dangerous when added to an already deep plane of anaesthesia, and oxygen want readily occurs under these conditions. The hyperventilation of oxygen want is usually masked or short-lived under the combined effect of deep anaesthesia, and a depressed respiratory centre and carotid body, and apnoea may then supervene with little warning.

(ii) Any hindrance to the free flow of gases through the airways, whether due to a mechanical obstruction, high viscosity and friction of gases, or poor elasticity of the lungs as in emphysema, causes an abnormal resistance to breathing. The grosser forms of increased resistance produce very obvious laboured breathing and cyanosis, but the consequences of a slight increase in resistance are more subtle. The first and almost immediate effect is a slowing and deepening of respiration so that the respiratory rate may be reduced to a quarter of the normal. This effect is produced because the lungs fill and empty slower than normal, delaying the HeringBreuer reflex. In addition, carbon dioxide accumulates, tending to deepen respiration. Ultimately, if the resistance is not removed, oxygen want develops, and the breathing then becomes a little faster in an attempt to take in more oxygen. Later still, the centre becomes "tired" through oxygen want, and after a period of shallow, rapid breathing, respiration ceases altogether. The amount of resistance and the time taken to produce fatigue of the centre varies in different people, and the centre may be so sensitive that even the barely perceptible resistance of a closed circuit machine quickly induces rapid shallow breathing. Such patients, rare though they are, cannot tolerate a closed method of administration, and an open method should be substituted for it.

(iii) During deep anaesthesia, when the patient has intercostal paralysis and he is "nigh unto death," his respirations often become infrequent, but shallow and jerky. These disturb the surgeon because the guts heave violently at each breath, and they upset the anaesthetist who may forget that the cure lies in lightening the anaesthesia. This type of respiration is commonly seen in children whom it is easy to anaesthetise deeply.

\section{PERIOdiC BREATHing (CHEYNE-STOKES BREATHING)}

This consists of alternating periods of shallow and deep breathing, with, maybe, a short apnoeic pause between the periods. It is seen in ordinary life during sleep and after a bout of deep breathing, but in anaesthesia, as in disease, it is an indication of suboxygenation of the respiratory centre.

(i) The first effect of oxygen want is to produce a compensatory hyperventilation, a carotid 
body reflex effect. This tends to lower the alveolar carbon dioxide, resulting in a period of shallow breathing during which time oxygen want is again felt, producing another bout of deep breathing, and so periodic breathing is started. Since its continuation is dependent on anoxia of the centre, the cure is to administer oxygen. This breaks the circle, and regular respiration is resumed. A small amount of carbon dioxide added to the oxygen will also help, by providing an extra stimulus to the now well-oxygenated centre.

(ii) Periodic breathing also occurs, just as it does apart from anaesthesia, during the recovery phase, after a period of apnoea due to a low carbon dioxide tension in the blood. In these cases, the first spontaneous stimulus causing a resumption of breathing is usually the oxygen lack occurring during the apnoea, and the periodic breathing, if it occurs, is a result of the temporary anoxia of the centre.

\section{ALTERATION IN LENGTH OF EXPIRATION AS COMPARED TO INSPIRATION}

As anaesthesia deepens from the Ist plane to the 3rd plane, expiration occupies a progressively longer time than inspiration, in the respiratory cycle. In addition, in deeper anaesthesia, the pause after expiration becomes more definite and prolonged. The breathing changes from being mainly inspiratory in light anaesthesia, to mainly expiratory in deep anaesthesia. This observation, most valuable as an aid in determining the depth of anaesthesia, fits in with the modern physiological conception of the medullary respiratory centres. As anaesthesia deepens, the inspiratory centre being the "higher," or phylogenetically more recent, is the first to be affected, until, in deep anaesthesia, the "lower" expiratory centre dominates the respiratory control.

\section{IRREGULAR BREATHING}

Automatic regular respiration is, of course, the cardinal sign of surgical anaesthesia. When the breathing becomes irregular it means that the anaesthesia is too light or too deep for the surgery being performed. Both these conditions are bad and must be immediately rectified.

(i) When the anaesthesia is too light, stimuli from the operation "get through" to the brain and cause reflex irregularity of the respiration. This is often accompanied by laryngeal spasm of varied intensity, which may be a hindrance to the anaesthetist because it prevents him getting more anaesthetic agent into the patient to deepen the anaesthesia.

(ii) Irregular respiration in deep anaesthesia when widely dilated pupils, dry conjunctivae and intercostal paralysis are present, is a sign of impending death, and must not be tolerated for a moment. The anaesthesia must be lightened, and the patient well oxygenated.

\section{SUMMARY}

\section{Apnoea.}

(a) Early in 3rd stage.

(i) Low $\mathrm{CO}_{2}$ following hyperventilation in induction.

(ii) Overdose of agent due to "forced" induction. (Anaesthetic concentration low in tissues, but high in brain.)

(b) Later.

(i) Reflexly from operation area or from larynx.

(ii) True overdose of agent.

(iii) Excess $\mathrm{CO}_{2}$.

(iv) $\mathrm{O}_{2}$ lack.

\section{Hyperventilation.}

(i) $\mathrm{CO}_{2}$ excess.

(ii) $\mathrm{O}_{2}$ lack. (Both (i) and (ii) occur when airway is obstructed.)

(iii) Reflexly in light anaesthesia from operation area. 
3. Slow respiration.

(i) Respiratory depression due to morphia given too soon before operation.

(ii) Increased resistance to breathing (slow and deep).

(iii) Deep anaesthesia (slow and shallow and jerky).

4. Periodic Breathing.

(i) Recovery stage from hyperventilation apnoea.

(ii) Oxygen want.

5. Alteration in length of expiration compared to inspiration.

Expiratory phase longer than inspiratory phase in deeper anaesthesia, and vice versa.

6. Irregular breathing.

(i) Reflexly in light anaesthesia.

(ii) Deep anaesthesia-impending death.

\section{FELLOWSHIP OF MEDICINE AND POST-GRADUATE MEDICAL ASSOCIATION MEMBERSHIP}

Only qualified medical practitioners may become Members or Associates of the Fellowship of Medicine. The subscription rate, dating from the month of joining, and including the PosTGraduate Medical Journal, are as follows:

\section{MEMBers: $£$ I Is. od. per annum.}

Associates: I5s. per annum.

Members and Associates are entitled to pay lower fees for attendance at Courses of instruction arranged by the Fellowship of Medicine. (Associates are members of Medical Societies affiliated to the Fellowship of Medicine-a list of these Societies may be obtained on application to the Fellowship.)

The subscription rate to the Post-Graduate Medical Journal for practitioners resident overseas is I2s. per annum, post free, and this rate is also payable during the war by any practitioner serving with H.M. Forces, whether at home or abroad. Subscribers at this rate are not entitled to pay the lower fees, quoted to Members and Associates, for attendance at Courses of instruction.

\section{H. K. LEWIS \& Co. Ltd.} Medical Publishers and Booksellers

\section{I36 GOWER STREET LONDON, W.C.I}

(Adjoining University College and Hospital)

Telephone: EUSton 4282 (5 lines).

Telegrams: Publicavit, Westcent, London.

\section{Medical Lending Library}

ANNUAL SUBSCRIPTION from ONE GUINEA

FOR THE CONVENIENCE OF POST GRADUATE STUDENTS SHORT PERIOD SUBSCRIPTIONS ARE ARRANGED-FOR THREE OR SIX MONTHS

Detailed Prospectus on application

READING ROOM FOR SUBSCRIBERS

NEW BOOKS ADDED IMMEDIATELY UPON PUBLICATION 